\title{
Acceptable water flow rate in sandy channels
}

\author{
Shakhboz Latipov ${ }^{1 *[0000-0002-4237-9034]}$, Jasur Sagdiyev ${ }^{2}$, Sobir Eshev ${ }^{1}$, Islom Kholmamatov ${ }^{1}$, \\ and Iroda Rayimova ${ }^{3}$ \\ ${ }^{1}$ Karshi engineering-economics institute, 180100 Karshi, Uzbekistan \\ ${ }^{2}$ Karshi branch of Tashkent Institute of Irrigation and Agricultural Mechanization Engineers, 180119 \\ Karshi, Uzbekistan \\ ${ }^{3}$ Tashkent Institute of Irrigation and Agricultural Mechanization Engineers, 100000 Tashkent, Uzbekistan
}

\begin{abstract}
A comparison of the values obtained with the experimental data on noneroding velocity in the article shows that the soil erosion in the experiments took place much earlier because our experiments were carried out in trapezoidal channels, based on experiments in wide rectangular channels.

Keywords. Analysis, trapezoidal channels, kinematic structure, experiments.
\end{abstract}

\section{Introduction}

In the initial stage of channel design, one of the main tasks of the hydraulic channel calculation is to determine the value of the allowable noneroding velocity and the dimensions of its cross-section, which ensures the strength of the channel and the stability of the structure. Proper selection of the maximum noneroding velocity values in the channel significantly reduces the planar and depth deformations that occur along the length of its channel. Several computational links have been proposed in the literature to determine the values of allowable eroding velocity and the dimensions of its cross-section [1-15].

Normative values of permissible velocities are taken according to the mechanical composition and density of the soil when the depth of the channel $H_{a v}=1 \mathrm{~m}$. This depth's value shows the difference between the permissible velocities obtained from the normative documents and the values of the velocities measured in nature.

Although the issue of the noneroding velocity of water flow has been dealt with since the seventeenth century to the present day, this question has not been fully resolved. Several empirical and semi-empirical formulas have now been proposed for the determination of leaching rates in bound and non-cohesive soils. These are mainly formed from different approaches to the boundary equilibrium of the particle or by introducing coefficients that take into account various factors affecting soil errosion [1,3,8], [11-18].

To calculate the water flow errosion resistance of soils, the method of shear forces (friction force or critical shear stress) acting on the particles at the bottom of the stream along the flow movement $T_{0}=\rho U_{0}$, i.e. corresponding to the onset of solid particle motion, is also used. This approach has been studied by many researchers [14-20].

\footnotetext{
*Corresponding author: shakhboz2016@mail.ru
} 
The purpose of this article is to obtain dependence for determining the discharge of bottom sediments in channels based on the author's experimental materials.

From the above literature analysis, we can see that the studies on the errosion rates that occur on the lateral slopes of trapezoidal channels are lacking. Therefore, in this work, we aimed to establish the noneroding velocities of the flow at the bottom and sides of the trapezoidal cut channels lying in non-cohesive soils [21-38].

\section{Methods}

The analytical research method was applied to assess the previously obtained field observation data and create a mathematical model.

\section{Results and discussion}

The flow in a stream erosion represents the active forces, while the soil properties represent the passive (resistance forces) forces. Let us consider the effect of flow hydraulic parameters on the flow of the stream.

Currently, the following two methods are used to model the strength of the river:

- noneroding velocity method showing the resistance of soils to erosion;

- The method of forces acting on the particles at the bottom of the channel along with the flow and releasing it (pulling force).

In general, the water flow rate of the canals should be such that there is no erosion, turbidity, and grass cover on the bottom and sides of the canal.

Among the existing formulas, the connections of non-cohesive soils proposed by Ts.E. Mirtskhulava [5] are considered to be theoretically based on the setting of eroding rates. This connection is based on the analysis of the uneven surface of the channel bottom, the conditions of equality of shear forces and forces acting by turbulent flow, and shear resistance forces, taking into account the state of fatigue of the soil from the total mass. The connection is expressed in the following formulas:

$$
\begin{gathered}
v_{\mathrm{r} . \mathrm{e}}=\left(\lg \frac{8.8 h}{d}\right) \sqrt{\frac{2 m}{0.44 \rho n}\left[g\left(\rho_{g r}-\rho\right) d+2 C_{k . m}^{n} k\right]} \\
v_{\Delta r . e}=1.25 \sqrt{\frac{2 m}{0.44 \rho n}\left[g\left(\rho_{g r}-\rho\right) d+2 C_{k m}^{n} k\right]}
\end{gathered}
$$

where $v_{r . e}$ is the allowable eroding velocity of the flow across the section; $v_{\Delta r . e}$ is the permissible velocity in front of the bottom of the stream at the height of the roughness $\Delta ; \rho_{g}$ and $\rho$ are the compatibility of soil particle material and water, $\mathrm{kg} / \mathrm{m}^{3}$, respectively; $d$ is the average particle diameter, $\mathrm{m} ; C_{k \cdot m}^{n}$ - weakened strength at breaking of non-cohesive soil, ie coefficient taking into account formation of significant tensile forces in fine-grained (when present $d<0.25 \mathrm{~mm}$ ) soils with this parameter, Pa; coefficient taking into account the effect of colloidal fluxes on the flow washout capacity. If the water content of clay particles is 0.1 $\mathrm{kg} / \mathrm{m}^{3}$, then $m=1$. If these particles are $0.1 \mathrm{~kg} / \mathrm{m}^{3}$ and more in the water, then $m>1 ; n-$ coefficient considers the velocity pulsation in the pre-flow zone; $k$-coefficient characterizing the possible deviation from the tensile force equal to the average $(k=0.5)$ value [5].

Experimental studies to determine the kinematic structure of the noneroding velocity and flow in non-cohesive soils were conducted in the laboratory of the Karshi engineeringEconomics Institute (Karshi, Uzbekistan).

Studies to determine the noneroding velocity of water flow were conducted in the trapezoidal (at slope ratio $m=2 ; 2.5 ; 3 ; 3.5$ ) channel model. 
Cracks were opened in the bottom, and sidewalls of the channel and metal cassettes filled with sand were placed in them. In this model, the noneroding velocity of the non-cohesive soils of the water stream was investigated.

Experiments were performed in the laboratory to establish the erosion rates of the following five different fractions of non-cohesive soil: $d_{\tilde{n} \tilde{d}} \leq 0.315 \mathrm{~mm} ; 0.315<d_{\tilde{n} \tilde{\delta}}<0.63$ $\mathrm{mm} ; 0.63<d_{\tilde{n} \delta}<1.25 \mathrm{~mm} ; 1.25<d_{\tilde{n} \delta}<2.50 \mathrm{~mm} ; 2.5<d_{\tilde{n} \delta}<5.0 \mathrm{~mm}$.

Table 1 shows the results of laboratory studies on the flow noneroding velocity in noncohesive soils.

Table 1. Results of laboratory studies on the flow noneroding velocity in non-cohesive soils.

\begin{tabular}{|c|c|c|c|c|c|c|c|c|c|c|}
\hline \multirow{2}{*}{$\begin{array}{l}\mathrm{N} \\
\mathrm{o}\end{array}$} & \multirow[b]{2}{*}{$\mathrm{mm}$} & \multirow{2}{*}{$\begin{array}{c}\mathrm{Q} \\
\mathrm{m}^{3} / \mathrm{sec}\end{array}$} & \multirow[b]{2}{*}{$\mathrm{m}$} & \multirow[b]{2}{*}{$h_{c p}, \mathrm{~m}$} & \multicolumn{5}{|c|}{$V_{n}, \mathrm{~m} / \mathrm{sec}[5]$} & \multirow{2}{*}{$\begin{array}{c}\mathrm{V}_{\mathrm{n}}, \mathrm{m} / \mathrm{sec} \\
{[5]}\end{array}$} \\
\hline & & & & & $\mathrm{m}=0$ & $\mathrm{~m}=2$ & $\mathrm{~m}=2.5$ & $\mathrm{~m}=3$ & $\mathrm{~m}=3.5$ & \\
\hline 1 & 2 & 3 & 4 & 5 & 6 & 7 & 8 & 9 & 10 & 11 \\
\hline \multirow{2}{*}{1} & \multirow{2}{*}{0.315} & 0.0016 & 2 & 0.04 & & 0.157 & & & & \\
\hline & & 0.0025 & 2 & 0.044 & 0.24 & & & & & 0.24745 \\
\hline \multirow{2}{*}{2} & \multirow{2}{*}{0.47} & 0.0018 & 2 & 0.032 & & 0.171 & & & & \\
\hline & & 0.0022 & 2 & 0.035 & 0.25 & & & & & 0.268095 \\
\hline \multirow{2}{*}{3} & \multirow{2}{*}{0.94} & 0.007 & 2 & 0.031 & & 0.2 & & & & \\
\hline & & 0.011 & 2 & 0.043 & 0.31 & & & & & 0.344567 \\
\hline \multirow{2}{*}{4} & \multirow{2}{*}{1.88} & 0.0125 & 2 & 0.078 & & 0.271 & & & & \\
\hline & & 0.017 & 2 & 0.091 & 0.39 & & & & & 0.489685 \\
\hline \multirow{2}{*}{5} & \multirow{2}{*}{3.75} & 0.034 & 2 & 0.122 & & 0.357 & & & & \\
\hline & & 0.038 & 2 & 0.132 & 0.52 & & & & & 0.654475 \\
\hline \multirow{2}{*}{6} & \multirow{2}{*}{0.315} & 0.002 & 2.5 & 0.045 & & & 0.21 & & & \\
\hline & & 0.0021 & 2.5 & 0.058 & 0.22 & & & & & 0.257059 \\
\hline \multirow{2}{*}{7} & \multirow{2}{*}{0.47} & 0.0016 & 2.5 & 0.031 & & & 0.2 & & & \\
\hline & & 0.0017 & 2.5 & 0.035 & 0.24 & & & & & 0.268095 \\
\hline \multirow{2}{*}{8} & \multirow{2}{*}{0.94} & 0.003 & 2.5 & 0.038 & & & 0.28 & & & \\
\hline & & 0.0047 & 2.5 & 0.04 & 0.34 & & & & & 0.340412 \\
\hline \multirow{2}{*}{9} & \multirow{2}{*}{1.88} & 0.0046 & 2.5 & 0.05 & & & 0.33 & & & \\
\hline & & 0.0092 & 2.5 & 0.066 & 0.42 & & & & & 0.463706 \\
\hline \multirow{2}{*}{10} & \multirow{2}{*}{3.75} & 0.001 & 2.5 & 0.063 & & & 0.48 & & & \\
\hline & & 0.0016 & 2.5 & 0.079 & 0.54 & & & & & 0.595899 \\
\hline & & 0.002 & 3 & 0.034 & & & & 0.23 & & \\
\hline 11 & 0.011 & 0.0025 & 3 & 0.037 & 0.26 & & & & & 0.241423 \\
\hline 12 & 047 & 0.0019 & 3 & 0.033 & & & & 0.23 & & \\
\hline 12 & 0.47 & 0.0023 & 3 & 0.034 & 0.27 & & & & & 0.266897 \\
\hline 13 & 094 & 0.0025 & 3 & 0.037 & & & & 0.24 & & \\
\hline 10 & דינסט & 0.0046 & 3 & 0.045 & 0.35 & & & & & 0.347178 \\
\hline 14 & 188 & 0.004 & 3 & 0.041 & & & & 0.36 & & \\
\hline 17 & 1.00 & 0.0052 & 3 & 0.046 & 0.39 & & & & & 0.434506 \\
\hline 15 & 375 & 0.0043 & 3 & 0.066 & & & & 0.49 & & \\
\hline 10 & 8.70 & 0.0049 & 3 & 0.082 & 0.48 & & & & & 0.600152 \\
\hline
\end{tabular}




\begin{tabular}{|c|c|c|c|c|c|c|c|c|c|c|}
\hline \multirow{2}{*}{16} & \multirow{2}{*}{0.315} & 0.0024 & 3.5 & 0.036 & & & & & 0.25 & \\
\hline & & 0.0028 & 3.5 & 0.039 & 0.25 & & & & & 0.243254 \\
\hline \multirow{2}{*}{17} & \multirow{2}{*}{0.47} & 0.0031 & 3.5 & 0.041 & & & & & 0.26 & \\
\hline & & 0.0033 & 3.5 & 0.042 & 0.27 & & & & & 0.275632 \\
\hline \multirow{2}{*}{18} & \multirow{2}{*}{0.94} & 0.0036 & 3.5 & 0.043 & & & & & 0.28 & \\
\hline & & 0.0045 & 3.5 & 0.067 & 0.38 & & & & & 0.370045 \\
\hline \multirow{2}{*}{19} & \multirow{2}{*}{1.88} & 0.0042 & 3.5 & 0.066 & & & & & 0.37 & \\
\cline { 4 - 11 } & & 0.0046 & 3.5 & 0.068 & 0.42 & & & & & 0.46612 \\
\hline \multirow{2}{*}{20} & \multirow{2}{*}{3.75} & 0.0049 & 3.5 & 0.071 & & & & & 0.51 & \\
\cline { 3 - 11 } & & 0.0054 & 3.5 & 0.074 & 0.52 & & & & & 0.588439 \\
\hline
\end{tabular}

Fig. 2 shows the curves connecting the bottom diameter of the channel $\vartheta_{p}=\sqrt{2} \vartheta_{n}$ and the average diameter of the eroding velocity for the different slopes.

Experiments have shown a decrease in noneroding velocities at the bottom of the channel and on the side slopes with a decrease in the average diameters of the soils used in the model (Fig. 2).

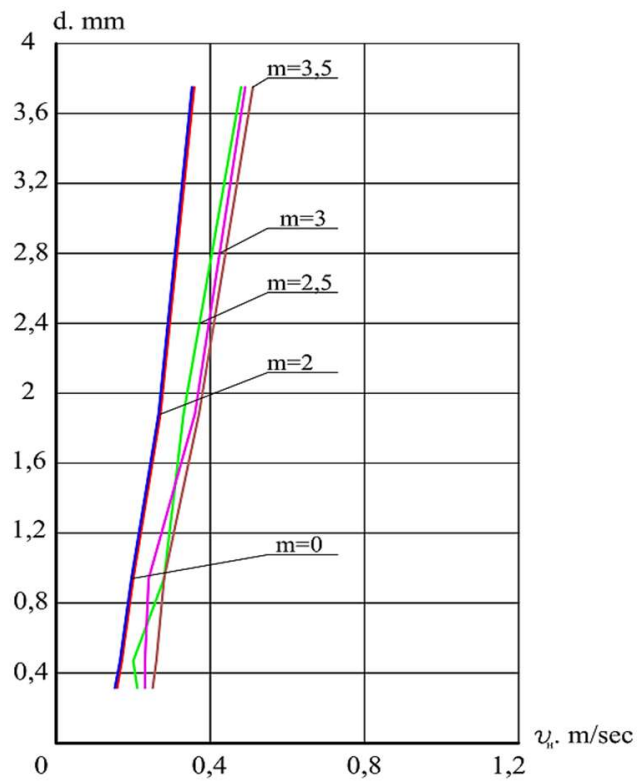

Fig. 2. Graph of correlation of granular soil particle sizes with flushing velocities of flow at channel bottom and side slopes.

Comparison of the values obtained from the experimental data on noneroding velocities with the values calculated by the Mirtskh ulava [5] formula shows that in the experiments, the erodion of the soils occurs much earlier (Table 1). The reason for this is based on the fact that although our experiments were performed under trapezoidal channels, the Ts.E. Mirtskhuluva formula was based on experiments performed under right-angled channels.

Also, Fig. 2 shows that the flushing velocities of the flow in channels with different side slopes vary according to these side slopes. From the graphs, an increase in the noneroding velocities of the channels is observed as the slope of the channel side slopes decreases.

Based on the experimental data, a velocity distribution diagram was constructed according to the flow depth (Fig. 3). In these diagrams, the preservation of the character of the change of velocities along the flow depth in different modes of flow is observed. In all 
experiments, it was observed that the smallest value of the flow velocity was below the bottom, and the largest value was below the flow level.

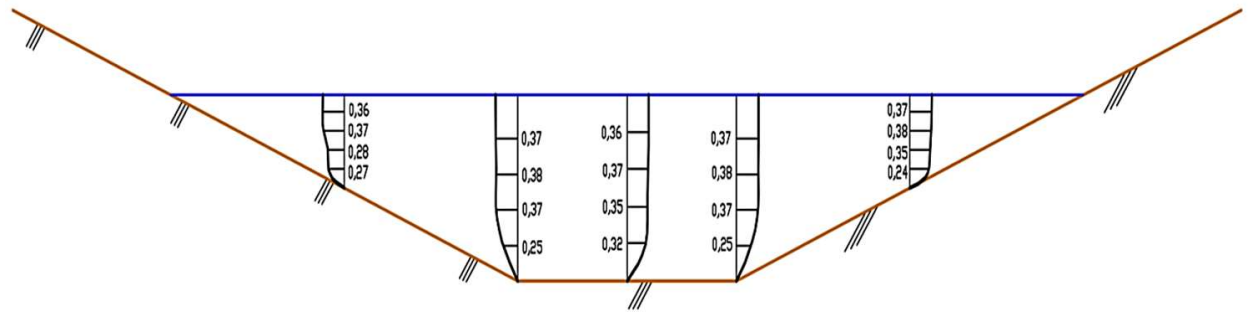

Fig. 3. Velocity distribution along the depth of water flow.

Hence, the pulsating nature of the load is an important factor in channel flushing and we have considered the need to take them into account when setting the channel flushing rate.

Analysis of the experimental results shows that the flattening of the velocities on the lateral slopes of the channel and the increase of the subsurface velocities lead to a violation of the law of local velocity distribution over the depth. From this we can conclude that in trapezoidal channels occurs a specific flow kinematic structure, which determines the condition for assessing the cross-sectional strength of the ground channel.

After processing the experimental survey data, the following coefficients were determined for the channels laid in the conditions of the study, ie on different side slopes: $m=2$ at $K_{0}=0.93 ; m=2$ at $K=0.76 ; m=2$ at $K=0.76 ; m=2$ at $K=0.76$.

In this case $K_{0}$ and $K$ - are the coefficients that take into account the bottom and side slopes of the channel, respectively.

According to the results of the study, it was found that the average value of the coefficient for the channel bottom (when $m=0$ ) is equal $K_{0}=0.93$ and can be taken as $K_{0}=0.93$ the next place.

Developing research in this area, taking into account the effect of changes in the slope coefficients of the channel on the eroding processes in the trapezoidal channel, the following equations were recommended:

- for the bottom:

$$
\begin{aligned}
& \vartheta_{a d m}=K_{0}\left(\lg \frac{8.8 h}{d_{m}}\right) \sqrt{\frac{\gamma_{c}\left[g\left(\rho-\rho_{\omega}\right) d_{m}+2 C_{y n} k_{c}\right]}{0.22 \rho_{\omega} \gamma_{\vartheta}}} ; \\
& \vartheta_{\Delta a d m}=1.25 K_{0} \sqrt{\frac{\gamma_{c}\left[g\left(\rho-\rho_{\omega}\right) d_{m}+2 C_{y n} k_{c}\right]}{0.22 \rho_{\omega} \gamma_{\vartheta}}} ;
\end{aligned}
$$

- for different side slopes:

$$
\begin{aligned}
& \vartheta_{a d m}=K\left(\lg \frac{8.8 h}{d_{m}}\right) \sqrt{\frac{\gamma_{c}\left[g\left(\rho-\rho_{\omega}\right) d_{m}+2 C_{y n} k_{c}\right]}{0.22 \rho_{\omega} \gamma_{\vartheta}}} ; \\
& \vartheta_{\Delta a d m}=1.25 K \sqrt{\frac{\gamma_{c}\left[g\left(\rho-\rho_{\omega}\right) d_{m}+2 C_{y n} k_{c}\right]}{0.22 \rho_{\omega} \gamma_{\vartheta}}} ;
\end{aligned}
$$

Based on the analysis of the study results, it was determined that there is the following relationship between the ratios $K / K_{0}$ of the parameters of the stream $B / \chi$ :

$$
\frac{K}{K_{0}}=f\left(\frac{B}{\chi}\right)
$$

where $B$ - width of the water level; $\chi$ - wetting perimeter. 
The obtained experimental results were analyzed using mathematical statistical methods (correlation coefficient $R^{2}=0,96$ ) and the following expression was formed:

$$
\frac{K}{K_{0}}=0.96\left(\frac{B}{\chi}\right)^{0.25} \text {. }
$$

From the results of the analysis (Fig. 4) $K / K_{0}$, an increase in the ratio was also observed as the $B / \chi$ ratio increased.

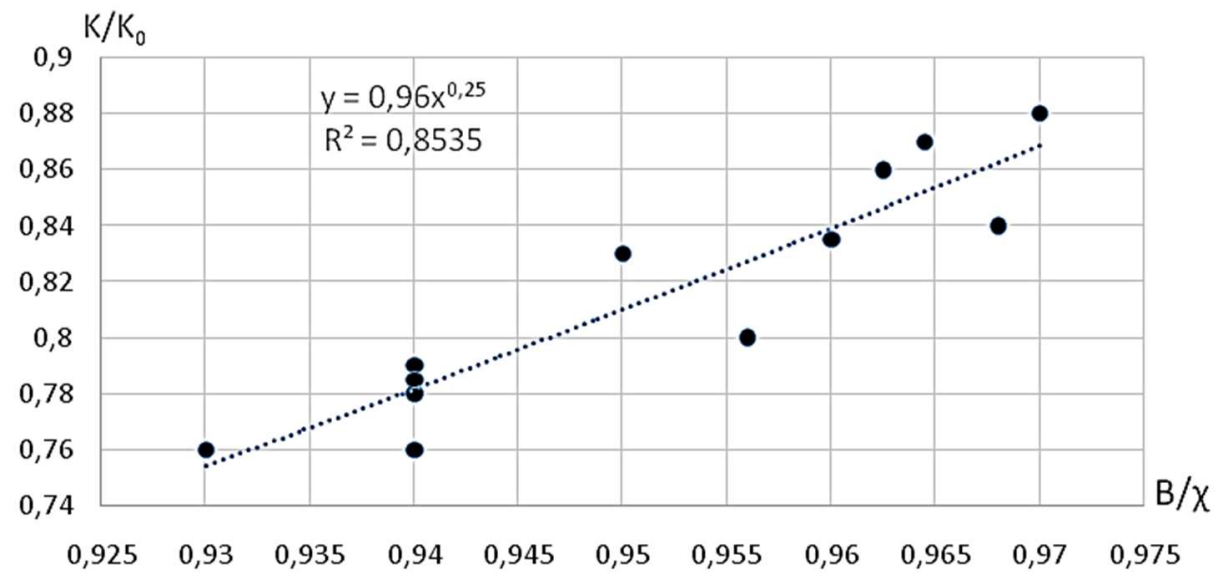

Fig. 4. $\frac{K}{K_{0}}=f\left(\frac{B}{\chi}\right)$ connection graph.

Comparison of the flow eroding rates calculated according to the improved formula (3) with the values calculated according to the formulas of several other authors $[3,20]$ gave satisfactory results.

The values of the flow eroding rates calculated according to formulas (3-6) showed satisfactory results with the values of the data obtained in the experiment (Fig. 5).

In the next phase of the study, the study of the transport process of the effluents in the non-cohesive soil trapezoidal canals was considered. For the calculation of the flow transport, the total flows are divided into the subsurface and suspended flows.

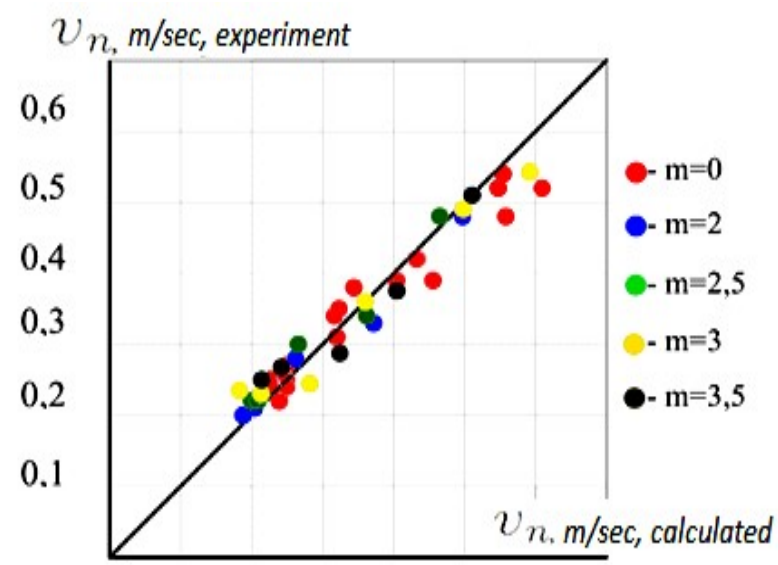

$\begin{array}{llllll}0.1 & 0,2 & 0.3 & 0.4 & 0.5 & 0.6\end{array}$

Fig. 5. Comparison of the calculated values of the experimental data (3-6) with the formulas. 


\section{Conclusions}

Not all factors were taken into account by Mirtskhulava [5]. For example, since the channel routing is not straight, the coefficient of its side slopes was not considered in the conditions mentioned above when setting the erosion rate in them. The results of the above-discussed experiment showed that this factor should be taken into account.

Hence, formulas (3-6) can be used to determine the erosion rates of the bottom and side slopes of trapezoidal channels laid in non-cohesive soils.

\section{References}

1. V.S. Altunin. Reclamation channels in earthen channels, M., 255 (1979).

2. V.S. Altunin, G.V. Simonov, A.A. Tursunov, P.G. Fialkovsky. Design and hydraulic calculation of large earth canals, Hydraulic engineering and melioration 7, 16-20 (1981).

3. S. Eshev, Sh. Latipov, A. Qurbonov, J. Sagdiyev, M. Berdiev, N. Mamatov. Non-eroding velocity of water flow of channels running in cohesive soils, IOP Conf. Series: Materials Science and Engineering 1030, (2021). DOI: 10.1088/1757-899X/1030/1/012131.

4. I.F. Karasev. Complexes of similarity and hydraulic resistance of self-forming river beds and canals, Hydraulic engineering 12, 27-31 (2006).

5. T.E. Mirtskhulava. Erosion of channels and methods for assessing their stability, M., 179 (1967).

6. M.V. Shmakova, S.A. Kondratev. Analysis and calculations of solid runoff (on the example of North American rivers), Uchen. app. RSHMU 43, 51-66 (2016).

7. S.S. Eshev. Calculation of deformations of large earth canals under conditions of stationary water flow, Tashkent, 168 (2017).

8. S.S. Eshev, A.M. Fatxullaev, L.N. Samiev, I.G. Axmedov, X. Jumaboev, S. Arifjanov. Determination of leaching rates in non-cohesive soils, Irrigation and reclamation 1 (15), 27-30 (2019).

9. E. Akkuzu, H. Unal, B. Karatas, M. Avci, S. Asik. Evaluation of Irrigation Canal Maintenance according to Roughness and Active Canal Capacity Values, J. Irrig. Drain Eng. 134, 60-66 (2008).

10. S. Aleksandrov, A. Krek, E. Bubnova, A. Danchenkov. Eutrophication and effects of algal bloom in the south-western part of the Curonian Lagoon alongside the Curonian Spit, Baltica 31, 1-12 (2018).

11. G. Bombar, Ş. Elçi, G. Tayfur, M.Ş. Güney, A. Bor. Experimental and numerical investigation of bed-load transport under unsteady flows, Journal of Hydraulic Engineering 137 10, 1276-1282 (2011).

12. S.R. Chalov, A.S. Tsyplenkov. Short-term dynamics of river water turbidity, Geography and tourism, Institute of Geography, Kazimierz Wielki University, Poland (Bydgoszcz) 6 1, 7-14 (2018).

13. C. Ferrarin, G. Umgiesser, A. Roland, M. Bajo, F. de Pascalis, M. Ghezzo, I. Scroccaro. Sediment dynamics and budget in a microtidal lagoon - A numerical investigation, Mar. Geol. 381, 163-174 (2016).

14. E. Kari, S. Kratzer, J.M. Beltrán-Abaunza, E.T. Harvey, D. Vaičiūtè. Retrieval of suspended particulate matter from turbidity-model development, validation, and application to Meris data over the Baltic Sea, Int. J. Remote Sens. 38, 1983-2003 (2017).

15. R. Kiyoumars, Sh. Saman. Prediction of sediment transport rates in gravel-bed rivers using Gaussian process regression, Journal of Hydroinformatics 22 (2), 249-262 (2020). 
16. K.T. Lee, Y.L. Liu, K.H. Cheng. Experimental investigation of bed-load transport processes under unsteady flow conditions, Hydrological Processes 18 (13), 2439-2454 (2004).

17. F. Maicu, F. de Pascalis, C. Ferrarin, G. Umgiesser. Hydrodynamics of the Po RiverDelta-Sea System, J. Geophys. Res. Ocean. 123, 6349-6372 (2018).

18. S. Eshev, A. Rakhimov, I. Gayimnazarov, A. Isakov, B. Shodiev, F. Bobomurodov. Dynamically stable sections of large soil canals taking into account wind Waves, IOP Conf. Series: Materials Science and Engineering 1030, (2021). DOI: 10.1088/1757899X/1030/1/012134.

19. S. Eshev, A.N. Khazratov, A.R. Rakhimov, Sh.A. Latipov. The study of bottom sediments in streams with mixed movement of clarified flow, International Multidisciplinary Research Journal 9 (9), 61-66 (2019).

20. S.S. Eshev, M.I. Rakhmatov, O.S. Nurova. Investigation of non-eroding flow rates in trapezoidal channels running in non-cohesive soils, Agriculture of Uzbekistan 3, 58-59 (2011).

21. A.R. Khafizov, F.F. Kamaletdinov, A.B. Yakushkina, I.V. Nedoseko. Construction regulatory systems to protect the banks of the Ufa river in the area of Ufa water intake, Izvestiya KGASU 1 (51), 118-127 (2020).

22. B. Obidov, O. Vokhidov, D. Tadjieva, U. Kurbanova, A. Isakov. Hydrodynamic effects on the flow elements of the downstream devices in the presence of cavitation, IOP Conf. Ser. Mater. Sci. Eng. 1030, 012114 (2021).

23. D. Bazarov, B. Norkulov, O. Vokhidov, F. Uljaev, Z. Ishankulov. Two-dimensional flow movement in the area of protective regulatory structures, IOP Conf. Ser. Mater. Sci. Eng. 890, 012162 (2020).

24. R.Kh. Mukhametrakhimov, I.R. Aliullova. Improvement of the quality control system for expansion joints with rubber compensators during the repair of bridge constructions, Izvestiya KGASU 3 (53), 47-55 (2020).

25. R.Kh. Mukhametrakhimov, A.A. Panchenko. Features of the quality control system for the construction of outdoor water supply and sewerage networks, Izvestiya KGASU 4 (42), 360-367 (2017).

26. R.H. Mukhametrakhimov, A.A. Panchenko. Features of technology of installation and quality control of pipelines with polyfoam polyethylene insulation, Izvestiya KGASU 2 (44), 246-254 (2018).

27. D. Bazarov, N. Vatin, B. Obidov, O. Vokhidov. Hydrodynamic effects of the flow on the slab of the stand in the presence of cavitation, IOP Conf. Ser. Mater. Sci. Eng. 1030, 012110 (2021).

28. D. Bazarov, I. Markova, B. Norkulov, O. Vokhidov. Hydraulic aspects of the layout of head structures during water intake from lowland rivers, IOP Conf. Ser. Mater. Sci. Eng. 1015, 012041 (2021).

29. A. Krutov, R. Choriev, B. Norkulov, D. Mavlyanova, A. Shomurodov. Mathematical modelling of bottom deformations in the kinematic wave approximation, IOP Conf. Ser. Mater. Sci. Eng. 1030, 012147 (2021).

30. A. Krutov, B. Norkulov, F. Uljaev, F. Jamalov. Results of a numerical study of currents in the vicinity of a damless water intake, IOP Conf. Ser. Mater. Sci. Eng. 1030, 012121 (2021).

31. A. Krutov, B. Norkulov, D. Mavlyanova. Simulation of spreading of non-conservative passive substances in water bodies, IOP Conf. Ser. Mater. Sci. Eng. 883 (1), 012028 (2020). 
32. A. Krutov, B. Norkulov, P. Nurmatov, M. Mirzaev. Applicability of zero-dimensional equations to forecast nonconservative components concentration in water bodies, IOP Conf. Ser. Mater. Sci. Eng. 883 (1), 012028 (2020).

33. A. Krutov, B. Norkulov, F. Artikbekova, P. Nurmatov. Optimal location of an intake at a reservoir prone to salt diffusion, IOP Conf. Ser. Mater. Sci. Eng. 869 (7), 072020 (2020).

34. B. Shokirov, B. Norkulov, Kh. Nishanbaev, M. Khurazbaev, B. Nazarov. Computer simulation of channel processes, E3S Web of Conferences 97, 05012 (2019).

35. M. Shomayramov, B. Norkulov, J. Rakhmanov, D. Tadjiyeva, J. Suyunov. Experimental researches of hydraulic vacuum breakdown devices of siphon outlets of pumping stations, E3S Web of Conferences 97, 05009 (2019).

36. D. Bazarov, I. Markova, S. Sultanov, F. Kattakulov. Dynamics of the hydraulic and alluvial regime of the lower reaches of the Amudarya after the commissioning of the Takhiatash and Tuyamuyun hydrosystems, IOP Conf. Ser. Mater. Sci. Eng. 1030, 012110 (2021).

37. D. Bazarov, O. Vokhidov. Extinguishing Excess Flow Energy in Spillway Structures. In book: Proceedings of EECE 2020, LNCE 150, 535-545 (2021). DOI: 10.1007/978-3-03072404-7_52.

38. D. Bazarov, I. Markova, B. Norkulov, K. Isabaev, M. Sapaeva. Operational efficiency of water damless intake, IOP Conf. Ser. Mater. Sci. Eng. 869 (7), 072051 (2020). 